\title{
Determinação de parâmetros cinéticos da inativação térmica de Escherichia coli em lodo de esgoto
}

\section{Determining kinetic parameters for thermal inactivation of Escherichia coli in sewage sludge}

\author{
Odinei Fogolari \\ Engenheiro Químico. Mestre em Engenharia Ambiental. Departamento de Engenharia Sanitária e Ambiental da Universidade Federal de Santa Catarina \\ (UFSC) - Florianópolis (SC), Brasil.
}

\section{Crisleine Zottis dos Reis}

Engenheira Química. Doutoranda em Engenharia Química. Departamento de Engenharia Química e de Engenharia de Alimentos da UFSC - Florianópolis (SC), Brasil.

\author{
Luiz Sérgio Philippi \\ Doutor em Hidrologia e Saúde Pública pela Université de Montpellier I. Professor do Departamento de Engenharia Sanitária e Ambiental e do Programa de \\ Pós-graduação em Engenharia Ambiental da UFSC - Florianópolis (SC), Brasil.
}

\section{Resumo}

O presente trabalho objetivou determinar parâmetros cinéticos da inativação térmica de Escherichia coli em lodo de esgoto. Os ensaios foram realizados em laboratório pelo método do frasco de três bocas nas temperaturas de 45, 50, 55, 60 e $65^{\circ} \mathrm{C}$. Os resultados indicaram que a cinética de inativação térmica deste microrganismo pode ser descrita por um modelo de primeira ordem. A resistência da bactéria é reduzida consideravelmente em temperaturas acima de $55^{\circ} \mathrm{C}$. A energia de inativação encontrada foi $2,48 \times 10^{5} \mathrm{~J} \cdot \mathrm{mol}^{-1}$. O tempo de redução decimal $D_{55^{\circ} \mathrm{C}}$ foi de 3,61 minutos e o coeficiente térmico $z$ foi $8,3^{\circ} \mathrm{C}$.

Palavras-chave: lodo de esgoto; Escherichia coli; inativação térmica; parâmetros cinéticos.

\begin{abstract}
The present study aimed to determine the kinetic parameters of thermal inactivation of Escherichia coli in sewage sludge. The tests were performed in the laboratory using the three-neck flask method at temperatures of $45,50,55,60$ and $65^{\circ} \mathrm{C}$. The results indicated that the thermal inactivation kinetic of this microorganism can be described by a first order model. The resistance of bacteria is greatly reduced at temperatures above $55^{\circ} \mathrm{C}$. The inactivation energy was found $2.48 \times 10^{5} \mathrm{~J}_{\mathrm{mol}}^{-1}$. The decimal reduction time $D_{55^{\circ} \mathrm{C}}$ was 3.61 minutes and the thermal coefficient $z$ was $8.3^{\circ} \mathrm{C}$.
\end{abstract}

Keywords: sewage sludge; Escherichia coli; thermal inactivation; kinetic parameters.

\section{Introdução}

O lodo de esgoto pode ser considerado uma fonte de nutrientes para a agricultura. Contudo, sua utilização desperta preocupações associadas à transmissão de patógenos para alimentos ou trabalhadores rurais, à contaminação de águas subterrâneas e superficiais, além do possível acúmulo de metais e contaminantes orgânicos no ambiente. Com isso, pesquisadores e gestores públicos de diversos países têm lançado esforços a fim de normatizar e aprimorar técnicas de tratamento que possibilitem o uso do lodo com segurança (WHO, 2006; VENGLOVSKY; MARTINEZ; PLACHA, 2006).

No Brasil, a Resolução n 375/2006 do Conselho Nacional do Meio Ambiente (CONAMA) define critérios e procedimentos para o uso agrícola de lodo de esgoto, classificando-o em duas categorias ( $\mathrm{A}$ e B) de acordo com as concentrações máximas de agentes patogênicos em cada uma delas. Para coliformes termotolerantes 
são exigidos menos de $10^{3} \mathrm{NMP}^{-1}$ de sólidos totais (ST) para o lodo Classe A e menos de $10^{6} \mathrm{NMP}^{-1}$ de ST para o lodo Classe B (BRASIL, 2006).

Nos Estados Unidos, a U.S. Environmental Protection Agency, que regulamenta o uso de lodo de esgoto, também o classifica em duas categorias (Classes A e B) de acordo com a sua qualidade, estabelecendo requisitos diferentes para cada uma delas (USEPA, 2003). A norma brasileira apresenta semelhança em vários aspectos com a americana, como por exemplo, na concentração de coliformes fecais para o lodo Classe A, que também deve ser inferior a $10^{3} \mathrm{NMP.g}^{-1}$ de ST, e para o lodo Classe B que deve ser inferior a $2 \times 10^{6} \mathrm{NMP}^{-1}{ }^{-1}$ de ST. Entretanto, divergem em outros quesitos, um exemplo é a concentração de ovos de helmintos no lodo Classe B, em que a norma brasileira impõe limite de 10 ovos. g $^{-1}$ de ST, já a americana não exige redução deste parâmetro, mas faz severas restrições ao uso do lodo enquadrado nesta classe.

A Resolução CONAMA no 375/2006 apresenta diversos processos de tratamento que podem ser utilizados para redução significativa ou redução adicional de agentes patogênicos no lodo. Dentre estes processos, estão incluídos os que utilizam calor úmido, com destaque para a secagem térmica; o tratamento térmico definido pelo aquecimento a $180^{\circ} \mathrm{C}$ por 30 minutos; e a pasteurização que consiste no aquecimento a $70^{\circ} \mathrm{C}$ por 30 minutos. Todos estão categorizados no item de redução adicional de patógenos, indicados para obtenção de lodo Classe A

O calor é um dos métodos mais empregados para inativar microrganismos. Estes são considerados inativados quando perdem, de forma irreversível, a capacidade de se multiplicar. Os microrganismos morrem pela desnaturação de proteínas na presença de calor úmido, ou por oxidação, quando se trata de calor seco. Quando uma população microbiana é aquecida, a redução do número de organismos viáveis ocorre em taxas elevadas, contudo, há variações de resistência de organismo para organismo (ALTERTHUM; CARVALHAL, 1999).

Pode-se destacar dois parâmetros importantes no processo de inativação térmica: tempo de redução decimal $\left(D_{\mathrm{T}}\right)$, que expressa o tempo, em minutos, necessário para redução de uma unidade logarítmica na concentração de células viáveis a uma dada temperatura (T); e o coeficiente térmico (z), que representa a diferença de temperatura necessária para a redução de uma unidade logarítmica no valor de $D_{T}$. Ambos estão relacionados com o grau de resistência ao calor de um determinado microrganismo (HAUG, 1993).

A relação tempo-temperatura para cada microrganismo é específica e dependente das características do meio em que está inserido. Em meios mais nutritivos, com condições mais favoráveis à reprodução, há uma tendência da resistência aumentar.
Diversos modelos preditivos de inativação já foram desenvolvidos, mas nenhum é amplamente aceito como sendo capaz de descrever todos os dados experimentais, cada um aborda uma situação específica para um determinado microrganismo (PFLUG; HOLCOMB; GÓMEZ, 2001; LANG; SMITH, 2008).

De acordo com Haug (1993) e Stumbo (1973), a cinética de inativação térmica de muitos microrganismos, principalmente bactérias, pode ser modelada assumindo um decaimento de primeira ordem, conforme a Equação 1.

$\frac{d N}{d t}=-k_{d} \cdot N$

Onde,

$N$ : concentração de células viáveis;

t: tempo de tratamento;

$k_{\mathrm{d}}$ : taxa de inativação térmica.

Esta equação é válida para sistemas que exibem curvas de sobrevivência tipo exponencial à temperatura constante. Sistemas que não exibem essa característica exigem modelagem específica.

Diante da necessidade de exploração da resistência térmica de agentes patogênicos em lodo de esgoto, diversos estudos vêm sendo realizados a fim de determinar a cinética de inativação de microrganismos que possam servir de indicadores da eficiência do tratamento. Dentre eles pode-se destacar os trabalhos de Aitken et al. (2005), Lang e Smith (2008), Pecson et al. (2007) e MocéLlivina et al. (2003).

O objetivo deste estudo foi determinar parâmetros cinéticos da inativação térmica de Escherichia coli em lodo de esgoto líquido. O estudo foi desenvolvido por meio de testes laboratoriais de bancada, sendo uma etapa complementar à pesquisa realizada sobre a desinfecção térmica de lodo em reator piloto com energia solar, conforme Fogolari (2011).

\section{Material e Métodos}

\section{Caracterização do lodo de esgoto}

O lodo de esgoto utilizado neste estudo foi proveniente de um tanque séptico instalado no Centro de Treinamento da Empresa de Pesquisa Agropecuária e Extensão Rural de Santa Catarina (EPAGRI) em Florianópolis (SC).

A caracterização do lodo bruto é apresentada na Tabela 1 e foi obtida através de 15 amostragens realizadas entre dezembro de 2009 e setembro de 2010. 
Tabela 1 - Caracterização do lodo de esgoto do tanque séptico.

\begin{tabular}{|c|c|c|c|c|}
\hline Parâmetro & Método & Mínimo & Máximo & Média+DP \\
\hline $\mathrm{pH}$ & $\begin{array}{l}\text { Potenciométrico - Standard methods } 2320 \text { B } \\
\text { (APHA; AWWA; WEF, 1998) }\end{array}$ & 6,68 & 7,62 & $7,12 \pm 0,22$ \\
\hline Alcalinidade $\left(\mathrm{mg} \cdot \mathrm{L}^{-1}\right)$ & Titulométrico de líquido sobrenadante (SILVA, 1977) & 24 & 511 & $236 \pm 177$ \\
\hline DQO $\left(m g \cdot L^{-1}\right)$ & $\begin{array}{l}\text { Digestão em refluxo fechado - método colorimétrico - } \\
\text { Standard methods 5220D (APHA, 1998). }\end{array}$ & 2.300 & 26.175 & $14.253 \pm 8.014$ \\
\hline Amonia (mg. $\left.\mathrm{L}^{-1}\right)$ & Colorimétrico de Nessler (VOGEL, 1981). & 21,4 & 120,5 & $70,6 \pm 30,6$ \\
\hline Nitrato $\left(\mathrm{mg} \cdot \mathrm{L}^{-1}\right)$ & $\begin{array}{l}\text { Colorimétrico com brucina - Standard methods } \\
\text { (APHA; AWWA; WEF, 1998) }\end{array}$ & 0,5 & 5,3 & $1,4 \pm 1,2$ \\
\hline Ortofosfato (mg. $\left.\mathrm{L}^{-1}\right)$ & $\begin{array}{l}\text { Método do ácido Vanadomolibdato - Standard methods } \\
\text { (APHA; AWWA; WEF, 1998) }\end{array}$ & 6,8 & 67,3 & $40,5 \pm 15,7$ \\
\hline Sólidos totais $\left(\mathrm{mg} \cdot \mathrm{L}^{-1}\right)$ & $\begin{array}{l}\text { Gravimétrico -secagem a } 105^{\circ} \mathrm{C} \\
\text { (SILVA, 1977) }\end{array}$ & 2.067 & 9.819 & $4.465 \pm 1.961$ \\
\hline Sólidos totais voláteis $\left(\mathrm{mg} \cdot \mathrm{L}^{-1}\right)$ & Método gravimétrico - calcinado a $550^{\circ} \mathrm{C}$ (SILVA, 1977). & 879 & 4.930 & $2.035 \pm 1.013$ \\
\hline Teor de sólidos totais voláteis (\%) & Método gravimétrico - calcinado a $550^{\circ} \mathrm{C}$ (SILVA, 1977) & 38,9 & 51,1 & $45,2 \pm 4,2$ \\
\hline E. coli (NMP.100 mL-1) & Substrato Definido Colilert ${ }^{\circledR}$ & $1,00 \mathrm{E}+04$ & $1,26 \mathrm{E}+07$ & $2,30 \mathrm{E}+06$ \\
\hline Coliformes totais (NMP.100 mL-1) & Substrato Definido Colilert ${ }^{\circledR}$ & $3,16 \mathrm{E}+05$ & $2,51 \mathrm{E}+07$ & $8,18 \mathrm{E}+06$ \\
\hline
\end{tabular}

DQO: demanda química de oxigênio; E. coli: Escherichia coli; DP: desvio padrão.

As concentrações de E. coli e coliformes totais no lodo bruto variaram na ordem de $10^{4}$ a $10^{7} \mathrm{NMP} .100 \mathrm{~mL}^{-1}$. O método empregado para quantificação de coliformes totais e E. coli foi o do Substrato Definido Colilert $^{\circledR}$ — o-nitrofenil-b-D-galactopiranosídeo (ONPG) e 4-metilumbeliferil-b-D-glucuronídeo (MUG).

\section{Determinação da resistência térmica da Escherichia coli}

Preparação do inóculo

O inóculo foi preparado a partir de amostras de lodo coletadas no tanque séptico. Alíquotas de $50 \mathrm{~mL}$ de lodo bruto foram centrifugadas a $1.650 \mathrm{xg}$ por 15 minutos. Após a centrifugação, $40 \mathrm{~mL}$ do sobrenadante foram descartados e o restante guardado em recipiente estéril, por no máximo 6 horas, até sua utilização nos experimentos de inativação térmica. Antes do início de cada experimento, foi determinada a concentração de E. coli no inóculo.

Ensaios de inativação térmica

Os ensaios para determinação dos parâmetros cinéticos de inativação térmica da E. coli foram realizados em bancada pelo método do frasco de três bocas, adaptado de Stumbo (1973). O frasco consiste em um balão de três bocas, as quais são utilizadas para a inserção de termopares para monitoramento da temperatura; agitador mecânico; e pipetas para introdução do inóculo e retirada de amostras, conforme ilustrado na Figura 1.

O método do balão é utilizado para determinar a resistência térmica de microrganismos em temperaturas abaixo do ponto de

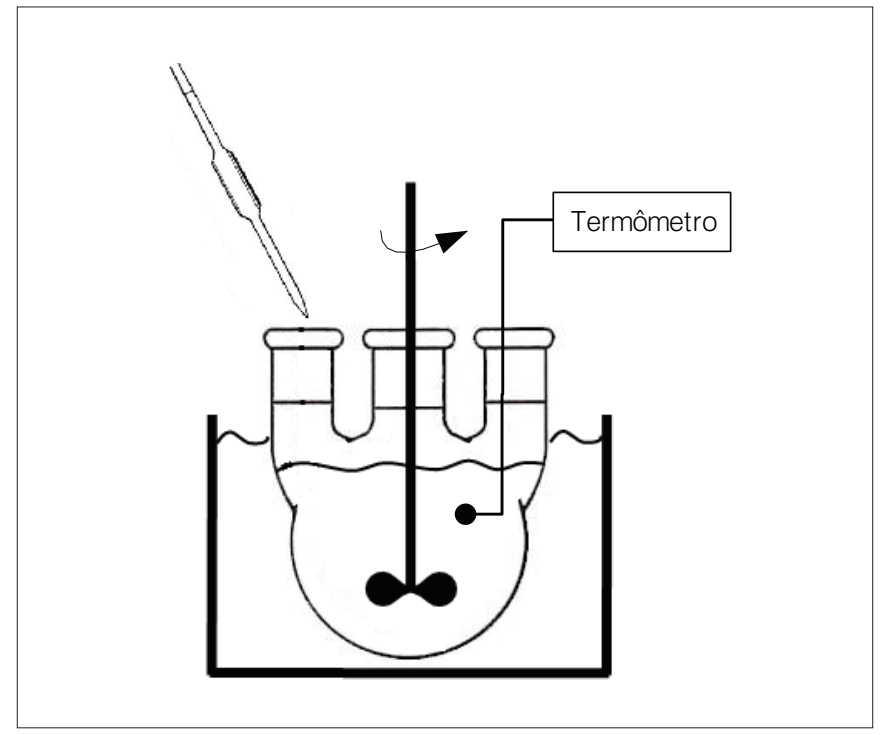

Figura 1 - llustração do aparato instrumental utilizado na realização dos ensaios.

ebulição da água à pressão atmosférica. O frasco é empregado para acondicionar a solução (meio reacional) durante o aquecimento. Quando a temperatura desejada é atingida, uma quantidade pequena de inóculo é adicionada ao meio, de modo a não causar mudanças consideráveis na temperatura. Exemplos de trabalhos que utilizaram essa metodologia com sucesso foram Augusto, Tribst e Cristianini (2009) e Reveron, Barreiro e Sandoval (2005).

Os testes de inativação da E. coli foram realizados em duplicata nas temperaturas de $45,50,55,60$ e $65^{\circ} \mathrm{C}$. O meio utilizado nos experimentos foi lodo de esgoto coletado no tanque séptico, 
previamente esterilizado em autoclave por 30 minutos a $121^{\circ} \mathrm{C}$, de forma a se obter material isento de qualquer microrganismo e não interferir, assim, na qualidade do inóculo adicionado posteriomente. Assim, a concentração inicial de E. coli na solução que é aquecida pode ser assumida como igual à concentração do inóculo, apenas levando em consideração a diluição do meio.

O balão contendo a suspensão de lodo de esgoto estéril (utilizada como meio reacional) foi fixado em um banho termostático com agitação. A temperatura da suspensão foi monitorada por dois termopares. Após o sistema atingir equilíbrio térmico na temperatura definida, adicionou-se $10 \%$ de inóculo preparado conforme o item anterior, completando um volume de $1 \mathrm{~L}$ de solução. Neste momento, iniciou-se o monitoramento do tempo de aquecimento e da concentração de E. coli na solução.

Amostras foram retiradas da solução em tempos predefinidos e colocadas rapidamente em banho de gelo. Após serem devidamente diluídas, as amostras receberam o substrato Colilert ${ }^{\circledR}$ e foram, em seguida, incubadas a $35^{\circ} \mathrm{C}$ por 24 horas até a contagem bacteriana.

\section{Análise dos dados}

Conforme já relatado, muitos microrganismos apresentam decaimento de primeira ordem quando submetidos ao aquecimento. Em processos nos quais a temperatura não sofre variações significativas, pode-se assumir $k_{\mathrm{d}}$ como constante. Assim, integrando a Equação 1 nas condições limites de concentração e temperatura e aplicando o logaritmo aos termos do resultado, chega-se à Equação 2, expressa a seguir.

$\ln N_{t}=\ln N_{0}-k_{d} t$

Onde,

$N_{t}$ : concentração de células no tempo $t$;

$N_{\mathrm{o}}$ : concentração de células em $t=0$ (inicial).

A taxa de inativação térmica $\left(k_{\mathrm{d}}\right)$ pode ser obtida por regressão linear dos dados de concentração microbiana versus tempo. Após a obtenção da taxa de inativação, o tempo de redução decimal $\left(D_{\mathrm{T}}\right)$ pode ser obtido pela Equação 3, o qual corresponde ao tempo necessário para redução de uma unidade logarítmica na concentração de células a uma dada temperatura:

$D_{T}=\frac{2,303}{k_{d}}$

A inativação térmica tem sido abordada frequentemente como uma reação química, sendo o modelo de Arrhenius, apresentado na Equação 4, usado para explicar o efeito da temperatura sobre a taxa de reação (HAUG, 1993; PFLUG; HOLCOMB; GÓMEZ, 2001):
$k_{d}=C \cdot \exp \left(-\frac{E_{d}}{R \cdot T_{K}}\right)$

Onde,

$T_{\mathrm{K}}$ : temperatura em Kelvin;

C: constante de inativação;

$E_{\mathrm{d}}$ : energia de inativação;

$R$ : constante dos gases $\left(R=8,3145 \mathrm{~J} \cdot \mathrm{K}^{-1} \cdot \mathrm{mol}^{-1}\right)$.

A energia de inativação $\left(E_{\mathrm{d}}\right)$ e a constante $C$ podem ser obtidas pela linearização da Equação 4, conforme segue (Equação 5).

$\ln k_{d}=\ln C-\left(\frac{E_{d}}{R}\right)\left(\frac{1}{T_{K}}\right)$

A Equação 5 pode ser representada genericamente por uma função de primeiro grau do tipo $\mathrm{Y}=\mathrm{B}+\mathrm{AX}$. Sendo assim, os parâmetros $E_{\mathrm{d}}$ e $C$ podem ser determinados por meio de regressão linear no gráfico de $\ln k_{\mathrm{d}} v s . T_{\mathrm{K}}^{-1}$.

\section{Resultados e Discussão}

\section{Resistência térmica da Escherichia coli}

A Figura 2 apresenta as curvas de inativação térmica da E. coli em lodo de esgoto obtidas nas temperaturas de 45, 50, 55, 60 e $65^{\circ} \mathrm{C}$. A Tabela 2 apresenta os valores da taxa de inativação térmica $\left(k_{\mathrm{d}}\right)$, além do tempo de redução decimal $\left(D_{\mathrm{T}}\right)$ (obtido pela Equação 3) em cada temperatura. O decaimento na concentração microbiana pode ser descrito por cinética de primeira ordem, sendo que o coeficiente de determinação $\left(R^{2}\right)$ das regressões lineares ficou acima de 0,93.

A utilização do modelo cinético de primeira ordem para determinação do valor de $D_{\mathrm{T}}$ de diferentes cepas de E. coli, também pode ser verificada em trabalhos como de Chung, Wang, Tang (2007), Jin et al. (2008) e Lang e Smith (2008).

Observa-se que a baixa taxa de inativação a $45^{\circ} \mathrm{C}$ ocasiona alto valor de $D_{\mathrm{T}}$, tendo sido necessários mais de 142 minutos para redução de uma unidade logarítmica, o que tornaria o processo de desinfecção térmica pouco recomendado se conduzido nesta condição.

Em $50^{\circ} \mathrm{C}$, o valor de $D_{\mathrm{T}}$ diminuiu para 25,93 minutos, sendo este ainda um valor alto, representando um tratamento de baixa intensidade. Já em $55^{\circ} \mathrm{C}$ ou mais, os valores de $D_{\mathrm{T}}$ são bastante reduzidos (menores que 3,61 minutos), o que implica a condição mais apropriada para o tratamento térmico de lodo de esgoto.

Vários autores determinaram valores de $D_{\mathrm{T}}$ para $E$. coli em diferentes meios. Lang e Smith (2008), utilizando sobrenadante de lodo 

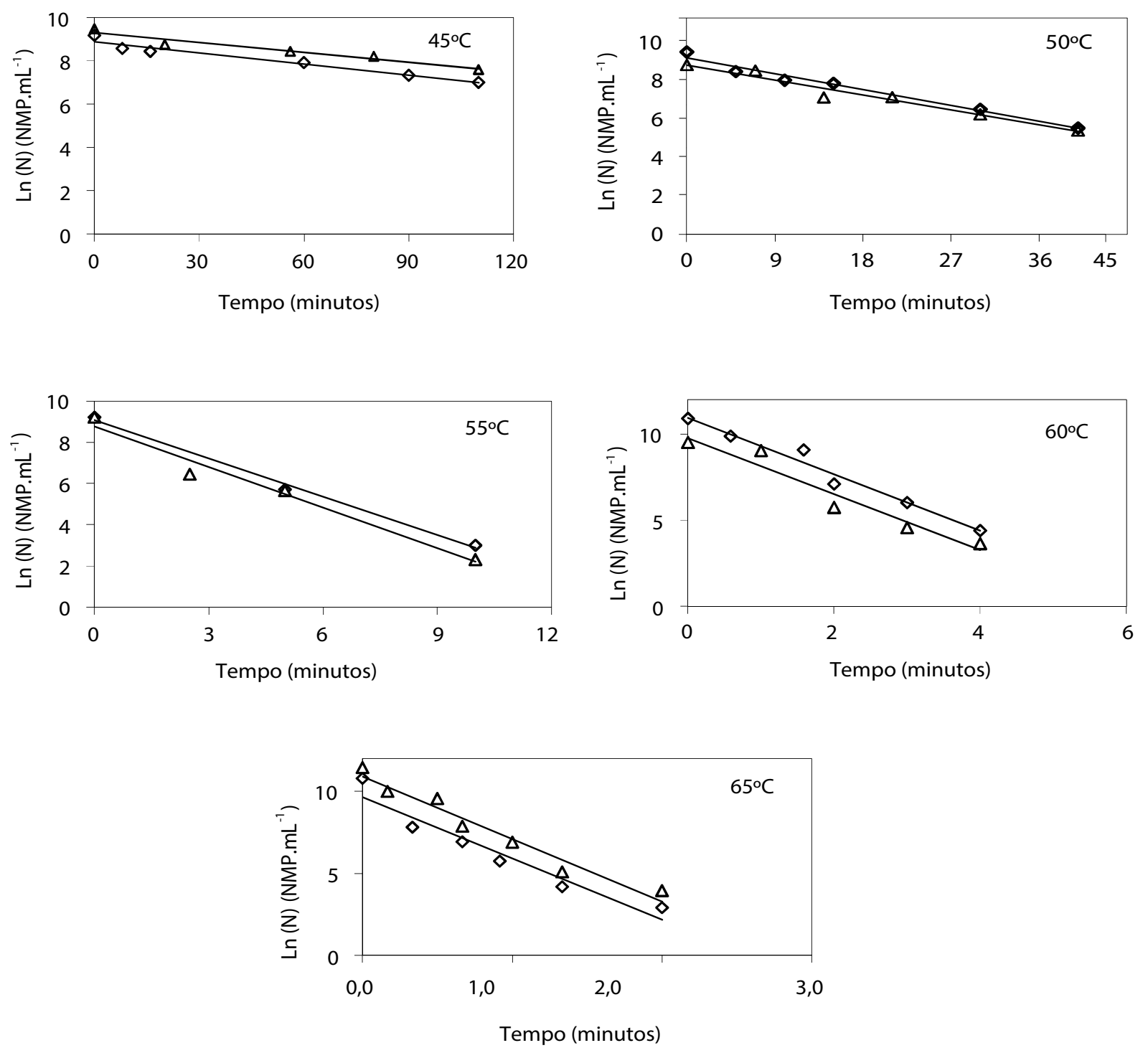

Figura 2 - Curvas de inativação térmica da Escherichia coli em lodo de esgoto a 45, 50,55, 60 e $65^{\circ} \mathrm{C}$, realizadas em duplicada ( $\diamond$ repetição 1 ; $\Delta$ repetição 2). Ln (N) representa o logaritmo da concentração de células (N) medida em NMP.mL-1.

Tabela 2 - Taxa de inativação térmica da Escherichia coli, coeficiente de determinação e tempo de redução decimal para cada temperatura.

\begin{tabular}{|c|c|c|c|c|c|}
\hline $\mathrm{T}\left({ }^{\circ} \mathrm{C}\right)$ & Repetição & $k_{d}\left(\right.$ minuto $\left.^{-1}\right)$ & $\mathrm{R}^{2}$ & $\mathrm{k}_{\mathrm{d}}$ (médio) & $\mathrm{D}_{\mathrm{T}}$ (médio) \\
\hline \multirow{2}{*}{45} & 1 & 0,0172 & 0,95 & \multirow{2}{*}{0,0162 minuto $^{-1}$} & \multirow{2}{*}{$D_{45^{\circ} \mathrm{C}}=142,68$ minutos } \\
\hline & 2 & 0,0152 & 0,94 & & \\
\hline 50 & 1 & 0,0912 & 0,98 & 0,0889 minuto $^{-1}$ & $D_{50^{\circ} \mathrm{C}}=25,93$ minutos \\
\hline \multirow{2}{*}{55} & 1 & 0,6215 & 0,99 & \multirow{2}{*}{0,6390 minuto $^{-1}$} & \multirow{2}{*}{$\mathrm{D}_{55^{\circ} \mathrm{C}}=3,61$ minutos } \\
\hline & 2 & 0,6564 & 0,97 & & \\
\hline \multirow{2}{*}{65} & 1 & 3,7461 & 0,93 & \multirow{2}{*}{3,7761 minuto $^{-1}$} & \multirow{2}{*}{$\mathrm{D}_{65^{\circ} \mathrm{C}}=0,61$ minutos } \\
\hline & 2 & 3,8060 & 0,96 & & \\
\hline
\end{tabular}

$k_{\mathrm{d}}$ : taxa de inativação térmica; $\mathrm{R}^{2}$ : coeficiente de determinação; $D_{\mathrm{T}}$ : tempo de redução decimal. 


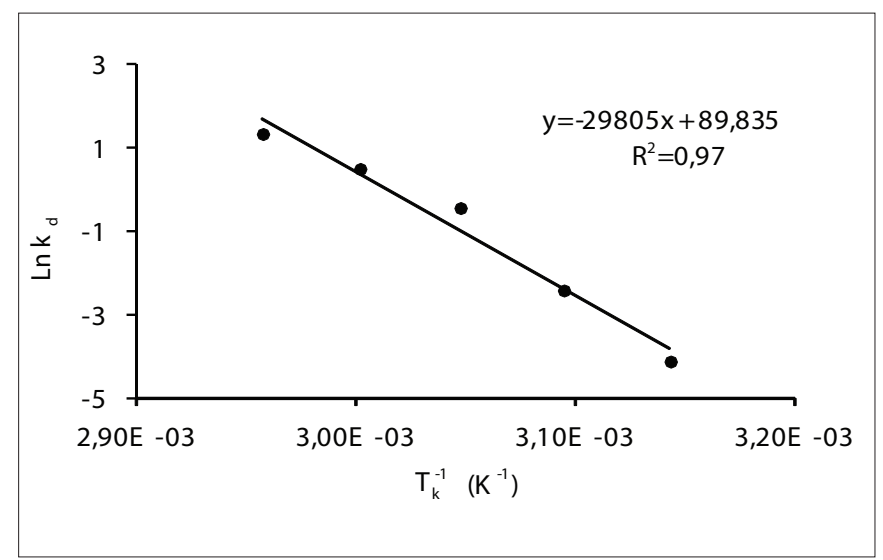

Figura 3 - Obtenção da energia de inativação térmica $E_{d}$ e da constante $C$ da Escherichia coli em lodo de esgoto.

líquido centrifugado, encontraram $\mathrm{D}_{55^{\circ} \mathrm{C}}=2,1$ minutos para a cepa NCTC 9001; $\mathrm{D}_{55^{\circ} \mathrm{C}}=2,4$ minutos para O148; $\mathrm{e}_{55^{\circ} \mathrm{C}}=2,6$ minutos para O158. Utilizando Caldo Triptona de Soja, os autores encontraram $\mathrm{D}_{55^{\circ} \mathrm{C}}=4,4$ minutos para NCTC $9001 ; \mathrm{D}_{55^{\circ} \mathrm{C}}=7,1$ minutos para O148; e $D_{55^{\circ} \mathrm{C}}=5,9$ minutos para $\mathrm{O} 158$. Revelando uma maior resistência do microrganismo em meio mais nutritivo.

Gabriel e Nakano (2009), realizando testes em suco de maçã, determinaram $D_{55^{\circ} \mathrm{C}}=4,43$ minutos para a cepa O157:H7 e $D_{55^{\circ} \mathrm{C}}=0,96$ minutos para K-12. Oteiza, Giannuzzi e Califano (2003), utilizando caldo nutritivo comercial como meio, determinaram $\mathrm{D}_{54^{\circ} \mathrm{C}}=4,5$ minutos; $\mathrm{D}_{58^{\circ} \mathrm{C}}=1,5$ minutos; e $\mathrm{D}_{62^{\circ} \mathrm{C}}=0,5$ minutos para a cepa G335. Spinks et al. (2006) encontraram $D_{55^{\circ} \mathrm{C}}=6,68$ minutos para $\mathrm{O} 3: \mathrm{H} 6$ e $\mathrm{D}_{55^{\circ} \mathrm{C}}=3,72$ minutos para $\mathrm{O} 157: \mathrm{H} 7$, ambos realizados em água deionizada.

Observa-se, pelos trabalhos citados, que os valores de $D_{\text {T }}$ podem variar conforme a cepa do microrganismo e o meio em que ela está inserida. Os valores encontrados nesse estudo, descritos na Tabela 2, não correspondem a nenhuma cepa específica, pois elas não foram pré-selecionadas no inóculo e o método de quantificação detecta todas as células de E. coli presentes, contudo, mostraram-se dentro do esperado, não se distanciando dos dados observados em outros trabalhos.

A dependência da taxa de inativação com a temperatura pode ser descrita pelo modelo de Arrhenius (Equação 4). A energia de inativação $\left(E_{d}\right)$ e a constante $C$ foram obtidas através da linearização deste modelo, expresso pela Equação 5, cuja reta está representada

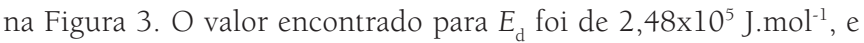
para a constante $C$ foi $1,03 \times 10^{39}$ minutos $^{-1}$. Esses parâmetros podem ser úteis na modelagem da inativação de processos que exibem um perfil de temperatura variável (HAUG, 1993; FOGOLARI, 2011).

Yaghmaee e Durance (2005) determinaram a energia de inativação térmica da E. coli (ATCC 11775) em suspensão aquosa e o valor encontrado foi $2,32 \times 10^{5} \mathrm{~J}_{\mathrm{mol}} \mathrm{m}^{-1}$, o que se aproxima muito do valor encontrado no presente trabalho.

O coeficiente térmico $z$ pode ser definido como a diferença de temperatura necessária para provocar a redução de um ciclo logarítmico no valor de $D_{\mathrm{T}}$. O valor de zé obtido através da curva de log $D_{\mathrm{T}}$ em função da temperatura. O valor encontrado foi de $8,3^{\circ} \mathrm{C}$, com coeficiente de determinação $\left(\mathrm{R}^{2}\right)$ de 0,97.

O valor de $z$ obtido esteve próximo a valores observados na literatura. Oteiza, Giannuzzi e Califano (2003) determinaram $z=7,9^{\circ} \mathrm{C}$ para a cepa G335 e z=7,8 ${ }^{\circ} \mathrm{C}$ para O157:H7); e Chung, Wang e Tang (2007), utilizando caldo BHI como meio, encontraram $z=6,5^{\circ} \mathrm{C}$ para a cepa $\mathrm{K}-12$.

De modo geral, os testes de inativação térmica da E. coli e os parâmetros cinéticos encontrados indicam que a desinfecção do lodo de esgoto pode atingir níveis consideráveis em temperaturas acima de $55^{\circ} \mathrm{C}$. Considerando os tempos de redução decimal obtidos, infere-se que 30 minutos de aquecimento do lodo em temperaturas superiores a $55^{\circ} \mathrm{C}$ seriam suficientes para redução de 6 unidades logarítmicas na concentração de E. coli, o que possivelmente permitiria enquadrá-lo como Classe A, com relação a coliformes termotolerantes, pela Resolução CONAMA nº 375/2006.

Deve-se considerar que os testes foram realizados em escala laboratorial e em condições controladas. Processos em escala real devem considerar outros fatores, como por exemplo, variações na temperatura, homogeneidade do meio, recrescimento microbiano, possíveis recontaminações durante e após o tratamento. Obviamente, para efetivação da segurança de um processo de inativação térmica, as cinéticas de outros microrganismos indicadores e patogênicos devem ser avaliadas. Cabe destacar que a Resolução CONAMA no 375/2006 estabelece concentrações limites para ovos viáveis de helmintos, Salmonella e vírus entéricos, além de coliformes termotolerantes.

A utilização da E. coli como único parâmetro da eficiência do tratamento térmico não é recomendada devido à grande variedade de microrganismos patogênicos que podem estar presentes no lodo, muitos deles apresentam resistência térmica considerável. Pode-se citar Lang e Smith (2008), que avaliaram a inativação térmica de diversas cepas de E. coli e Salmonella, sendo que a Salmonella Senftenberg $775 \mathrm{~W}$ foi a bactéria mais resistente do estudo, apresentando $\mathrm{D}_{55^{\circ} \mathrm{C}}=3,2$ minutos. Conforme observado nos trabalhos de Aitken et al. (2005) e Pecson et al. (2007), ovos de helmintos também podem apresentar resistência ao calor, sendo outro parâmetro essencial na avaliação de processos de desinfecção de lodo.

\section{Conclusões}

A inativação térmica da E. coli demonstrou seguir o modelo cinético de primeira ordem. O valor encontrado para a energia de inativação foi $2,48 \times 10^{5} \mathrm{~J} \cdot \mathrm{mol}^{-1}$, e para a constante $C$ foi $1,03 \times 10^{39} \mathrm{~min}^{-1}$. 
A resistência térmica da bactéria foi reduzida consideravelmente em temperaturas acima de $50^{\circ} \mathrm{C}$. O tempo de redução decimal $D_{55^{\circ} \mathrm{C}}$ foi de 3,61 minutos e o coeficiente térmico $z$ foi $8,3^{\circ} \mathrm{C}$. Considerando o agente microbiológico avaliado, observou-se que desinfecção térmica de lodo de esgoto líquido ocorreu com mais intensidade em temperaturas acima de $55^{\circ} \mathrm{C}$. Os resultados obtidos podem contribuir na avaliação dos fatores tempo-temperatura de inativação da E. coli, assim como fornecer dados complementares à modelagem de processos de higienização de lodo em escala real, visto que outros parâmetros também devem ser considerados para o atendimento das normas vigentes.

\section{Agradecimentos}

Os autores agradecem à Coordenação de Aperfeiçoamento de Pessoal de Nível Superior (CAPES) pela bolsade estudos e à Fundação Nacional de Saúde (FUNASA) pelo apoio financeiro concedidoà pesquisa pelo Edital 01/2007.

\section{Referências}

AITKEN, M.D; SOBSEY, M.D.; BLAUTH, K.E.; SHEHEE, M.; CRUNK, P.L.; WALTERS, G.W. (2005) Inactivation of Ascaris suum and poliovirus in biosolids under thermophilic anaerobic digestion conditions. Environmental Science \& Technology, v. 39, n. 15, p. 5804-5809.

ALTERTHUM, F.; CARVALHAL, M.L. (1999) Controle de microrganismos. In: TRABULSI, L.R. et al.. Microbiologia. 3. ed. São Paulo, Atheneu, p.75-86.

AMERICAN PUBLIC HEALTH ASSOCIATION; AMERICAN WATER WORKS ASSOCIATION; WATER ENVIRONMENT FEDERATION (APHA; AWWA; WEF). (1998) Standard Methods for the Examination of Water and Wastewater. 20th ed. Washington: APHA-AWWA-WEF, 1195 p.

AUGUSTO, P. E. D.; TRIBST, A. A. L.; CRISTIANINI, M. (2009) Thermal inactivation of Lactobacillus plantarum in a model liquid food. Journal of Food Process Engineering, v. 34, n.4, p. 1013-1027.

BRASIL. Ministério do Meio Ambiente. Conselho Nacional do Meio Ambiente. (2006) Resolução $n^{\circ} 375$ de 29 de agosto de 2006. Define critérios e procedimentos, para o uso agrícola de lodos de esgoto gerados em estações de tratamento de esgoto sanitário e seus produtos derivados, e dá outras providências. Disponível em: <http://www.mma.gov.br/port/conama/res/res06/res37506.pdf>. Acesso: 16 mai. 2011.

CHUNG, H.; WANG, S.; TANG, J. (2007) Influence of heat transfer with tube methods on measured thermal inactivation parameters for Escherichia coli. Journal of Food Protection, v. 70, n. 4, p. 851-859.

FOGOLARI, O. (2011) Desinfecção de lodo de tanque séptico em reator com aquecimento solar. 151 p. Dissertação (Mestrado em Engenharia Ambiental) - Universidade Federal de Santa Catarina, Florianópolis.

GABRIEL, A.A.; NAKANO, H. (2009) Inactivation of Salmonella, E. coli and Listeria monocytogenes in phosphate-buffered saline and apple juice by ultraviolet and heat treatments. Food Control, v. 20, n. 4 , p. $443-446$.

HAUG, R.T. (1993). The practical handbook of compost engineering. Boca Raton: Lewis. $717 \mathrm{p}$.
JIN, T.; ZHANG, H.; BOYD, G.; TANG, J. (2008) Thermal resistance of Salmonella enteritidis and Escherichia coli K12 in liquid egg determined by thermal-death-time disks. Journal of Food Engineering, v. 84, n. 4, p. 608-614.

LANG, N.L.; SMITH, S.R. (2008) Time and temperature inactivation kinetics of enteric bacteria relevant to sewage sludge treatment processes for agricultural use. Water Research, v. 42, n. 8-9, p. 2229-2241.

MOCÉ-LLIVINA, L.; MUNIESA, M.; PIMENTA-VALE, H.; LUCENA, F.; JOFRE, J. (2003) Survival of bacterial indicator species and bacteriophages after thermal treatment of sludge and sewage. Applied and Environmental Microbiology, v. 69, n. 3, p. 1452-1456

OTEIZA, J.M.; GIANNUZZI, L.; CALIFANO, A.N. (2003) Thermal inactivation of Escherichia coli O157:H7 and Escherichia coli isolated from morcilla as affected by composition of the product. Food Research International, v. 36, n. 7, p. 703-712.

PECSON, B.M.; BARRIOS, J.A.; JIMÉNEZ, B.E.; NELSON, K.L. (2007) The effects of temperature, $\mathrm{pH}$, and ammonia concentration on the inactivation of Ascaris eggs in sewage sludge. Water Research, v. 41 n. 13, p. 2893-2902.

PFLUG, I.J.; HOLCOMB, R.G.; GÓMEZ, M.M. (2001) Principles of the thermal destruction of microorganisms. In: Block, S.S. Disinfection, sterilization and preservation. 5th ed. Philadelphia, Lippincott Williams \& Wilkins. p.79-129.

REVERON, I.M.; BARREIRO, J.A.; SANDOVAL, A.J. (2005) Thermal death characteristics of Lactobacillus paracasei and Aspergillus niger in Pilsen beer. Journal of Food Engineering, v. 66, n. 2, p. 239-243.

SILVA, M.O.S.A. (1977) Análises físico-químicas para construção de estações de tratamento de esgotos. São Paulo, CETESB. 225 p.

SPINKS, A.T.; DUNSTAN, R.H.; HARRISON, T.; COOMBES, P.; KUCZERA, G. (2006) Thermal inactivation of water-borne pathogenic and indicator bacteria at sub-boiling temperatures. Water Research, v. 40, n. 6 , p. 1326-1332 
STUMBO, C.R. (1973) Thermobacteriology in food processing. 2nd ed. New York, Academic Press. 329 p.

UNITED STATES ENVIRONMENTAL PROTECTION AGENCY (USEPA). (2003) Control of Pathogens and Vector Attraction in Sewage S/udge. EPA/625/R-92/013, Revised jul. 2003. U.S. Environmental Protection Agency, Washington, DC.

VENGLOVSKY, J.; MARTINEZ, J.; PLACHA, I. (2006) Hygienic and ecological risks connected with utilization of animal manures and biosolids in agriculture. Livestock Science, v. 102, n. 3, p. 197-203.
VOGEL, A.I. (1981) Análise inorgânica qualitativa. 4a ed. Rio de Janeiro, Guanabara, 690 p.

YAGHMAEE, P.; DURANCE, T.D. (2005) Destruction and injury of Escherichia coli during microwave heating under vacuum. Journal of Applied Microbiology, v. 98, n. 2, p. 498-506

WORLD HEALTH ORGANIZATION (WHO). (2006) Guidelines for the safe use of wastewater, excreta and greywater. Volume 4: Excreta and greywater use in agriculture. Geneva, WHO. 182 p. 